\title{
The Influence of Maternal Factors on Children's Oral Health: Mothers' Age, Education Level, Toothbrushing Habit and Socioeconomic Status
}

\author{
(1) Berna Kuter1, (1) ilhan Uzel2 \\ ${ }^{1}$ izmir Demokrasi University Faculty of Dentistry, Department of Pediatric Dentistry, İzmir, Turkey \\ 2Ege University Faculty of Dentistry, Department of Pediatric Dentistry, İzmir, Turkey
}

\begin{abstract}
Aim: This study aimed to determine the influence of maternal factors on their children's oral health.

Materials and Methods: A total of 148 individuals aged between 5 and 14 years were included in this study. The children were randomly selected from their Dental Hospital Files. The oral hygiene habits and the examinations of the children and their mothers were evaluated. Clinical examination included decayed, missing or filled permanent teeth and decayed missed filled primary tooth indices. Statistical analyses were performed using Mann-Whitney, Kruskal-Wallis and Correlations test.

Results: The main finding of this study is that the mothers' socioeconomic status significantly affects their children's caries frequency. The caries incidence of those children whose mothers have high income was lower than those of children whose mothers have either moderate or low income. A relationship was found between the mothers' level of education and their children's toothbrushing habit. As the frequency of toothbrushing by the mothers increased, the frequency of toothbrushing by their children increased. It was found that as the mothers' age increased, the caries frequency of their children decreased.
\end{abstract}

Conclusion: A statistically significant result was found between the caries indices of children and the economic level of their mothers. A positive correlation between the mothers' level of education and the frequency of toothbrushing by their children was found.

Keywords: Caries, child, mother, socioeconomic status

\section{Introduction}

Caries is a public health problem, affecting both underdeveloped and industrialized nations (1). It is thought that caries are the most prevalent diseases in children and sugar is a significant factor in caries development together with poor oral hygiene (2). It was shown in one study about caries and their related factors in children that children who eat sweetened foods were more likely to have caries than children who do not have such nutritional habits (3). Other studies stated that the presence of caries was associated with a lower frequency of toothbrushing (4) and that children whose parents assisted them with toothbrushing had a better oral health status and lower caries scores (5). Furthermore, it was reported in another previous study that there was a relationship between the consumption of cariogenic foods and high caries risk (6). Adeniyi et al. (7) stated that maternal factors affected the oral health status of their children. It was also stated that mothers played an important role in reducing the risk of caries of their children. The findings of Shearer et al. (8) study put forward that 
mothers with poor oral health were likely to have children who also have poor oral health. Paglia stated that pediatric dentists should focus on the mother's education to prevent caries in their children (2). As a result of these findings, this study aimed to determine the influence of maternal factors on their children's oral health.

\section{Materials and Methods}

The dental examinations were carried out by one pedodontist using a dental mirror and explorer at a Pediatric Clinic at a Dental Hospital. A total of 148 individuals aged between 5 and 14 years and registered in the Dental Hospital files were included in this study. The children were randomly selected from the Dental Hospital Files. The files included the child's and parent's consent form, the child's age, gender, frequency of sugar intake, the mother's age, her education level, her toothbrushing habits and her socioeconomic status. The mothers' monthly income status was evaluated in three groups; low-income (0-200 $€)$, moderate-income (201-600 €) and high-income (601 € and over). Clinical examination included decayed, missing or filled permanent teeth (DMFT) and decayed missed filled primary tooth $(\mathrm{dmft})$ indices. Exfoliated teeth in primary and mixed dentition, unerupted teeth, and teeth extracted for other reasons apart from caries were not included in the indices. The inclusion criteria were children aged between 5-14 years. The exclusion criteria were the presence of a systemic disease or the inability to cooperate with the dental practitioner. Ethical approval for this study was given by the Ethics Committee of the University and Ministry of Health Provincial Health Directorate Dental Hospital Chief Physician (approval number: 2019/02)

\section{Statistical Analyses}

Statistical analyses were performed using MannWhitney, Kruskal-Wallis and Correlations test.

\section{Results}

The DMFT and dmft values of children are shown in Table I. The frequency of consuming sweets, the mother's age, her

Table I. Decayed missed filled teeth index for permanent dentition and $\mathrm{dmft}$ values of children

\begin{tabular}{|l|l|l|}
\hline Gender & DMFT \pm SD & DMFT \pm SD \\
\hline Girl & $2.71 \pm 0.65$ & $2.80 \pm 0.33$ \\
\hline Boy & $2.79 \pm 0.61$ & $2.17 \pm 0.48$ \\
\hline Total & $2.74 \pm 2.49$ & $2.61 \pm 2.36$ \\
\hline
\end{tabular}

DMFT: Decayed missed filled teeth index for permanent dentition, dmft: Decayed missed filled teeth index for primary dentition, SD: Standard deviation education level, tooth brushing habits, and monthly income are shown in Table II.

No statistically significant difference was found between boys and girls regarding the $\mathrm{dmft}$ index with the mixed dentition giving a $p=0.717>0.05$ and the DMFT index with permanent dentition giving a $p=0.238>0.05$ (MannWhitney U test).

Table II. The frequency of consuming sweets of children, monthly income, education level and ages of mothers, frequency of toothbrushing of children

\begin{tabular}{|l|l|}
\hline Frequency of consuming sweets of children & $\%$ \\
\hline Once a day & 27.0 \\
\hline $2-3$ times a day & 66.2 \\
\hline 4 or more times a day & 6.8 \\
\hline Monthly income & $\%$ \\
\hline Low income & 37.8 \\
\hline Moderate income & 54.1 \\
\hline High income & 8.1 \\
\hline Mother's education level & $\%$ \\
\hline Primary- secondary school & 68.3 \\
\hline High school & 19.5 \\
\hline University & 12.2 \\
\hline Mother's age & $\%$ \\
\hline $25-30$ & 12.3 \\
\hline $31-35$ & 22.4 \\
\hline $36-40$ & 34.7 \\
\hline $41-45$ & 20.4 \\
\hline $46-50$ & 6.1 \\
\hline $51-55$ & 4.1 \\
\hline Frequency of toothbrushing of children & $\%$ \\
\hline None & 16.2 \\
\hline Irregular & 83.8 \\
\hline $1-2$ times a day & 0 \\
\hline & \\
\hline & $\%$ \\
\hline
\end{tabular}

Table III. Association between caries of the children (DMFT, $\mathrm{dmft}$ ) and their mothers' monthly income

\begin{tabular}{|l|l|l|l|l|}
\hline \multicolumn{5}{|l|}{ Mother's monthly income } \\
\hline $\begin{array}{l}\text { Caries } \\
\text { value }\end{array}$ & $\begin{array}{l}\text { Low } \\
\text { income }\end{array}$ & $\begin{array}{l}\text { Moderate } \\
\text { income }\end{array}$ & $\begin{array}{l}\text { High } \\
\text { income }\end{array}$ & P \\
\hline DMFT & $2.71 \pm 2.35$ & $2.83 \pm 2.38$ & $0.67 \pm 1.63$ & 0.06 \\
\hline dmft & $3.31 \pm 2.52$ & $2.20 \pm 2.56$ & $3.00 \pm 2.00$ & 0.46 \\
\hline $\begin{array}{l}\text { DMFT: Decayed missed filled teeth index for permanent dentition, dmft: } \\
\text { Decayed missed filled teeth index for primary dentition }\end{array}$
\end{tabular}


It was shown that increasing DMFT scores in the children were associated with their frequency of consuming sweets $(p=0.036<0.05)$ (Kruskal-Wallis test). However, no relationship was found between the $\mathrm{dmft}$ scores of children and their frequency of consuming sweets $(p=0.179>0.05)$ (Kruskal-Wallis test).

No relationship was found between the DMFT of children and their parent's monthly income $(p=0.461>0.05)$ (KruskalWallis test) Table III. However, there was a relationship between the DMFT scores of the children and their parent's monthly income. The DMFT scores of those children whose parents had high income were lower than those of children whose parents had a moderate income $(p=0.021<0.05)$ (Kruskal-Wallis test). Additionally, the DMFT values of those children whose parents had high income were lower than that of those children whose parents had low income ( $p=0.042<0.05)$ (Kruskal-Wallis test) Table III.

There was a relationship between the DMFT values of the children and the age of their mothers. As the age of the mothers increased, the DMFT values of their children decreased in the groups with the mothers' ages between 31-45 ( $p=0.014<0.05)$ (Correlations test). There was no relationship between the DMFT values of the children and the age of their mothers in the other age groups.

As the frequency of toothbrushing of the mothers increased, the frequency of toothbrushing of their children increased $(p<0.05)$. There was no relationship between the frequency of the mothers' toothbrushing and the number of caries of their children ( $p>0.05)$ (Kruskal-Wallis test) Table IV.

As the mothers' level of education increased, the frequency of toothbrushing of their children increased $(p<0.05)$ (Kruskal-Wallis test). There was no relationship between the mother's level of education and the number of caries of their children ( $p>0.05$ ) (Mann-Whitney $U$ test) Table $V$. There was no relationship between the mothers' level of education and the frequency of consuming sweets of their children ( $p=0.235>0.05)$ Table VI.

Table IV. Association between caries of the children (DMFT, $\mathrm{dmft}$ ) and their their mothers' toothbrushing frequency

\begin{tabular}{|l|l|l|l|l|}
\hline & \multicolumn{4}{|l|}{ Mother's toothbrushing frequency } \\
\hline Caries value & $\begin{array}{l}\text { Irregular } \\
\text { Mean } \pm \text { SD }\end{array}$ & $\begin{array}{l}\text { 1x/day } \\
\text { Mean } \pm \text { SD }\end{array}$ & $\begin{array}{l}\mathbf{2 x / d a y} \\
\text { Mean } \pm \text { SD }\end{array}$ & $\mathbf{p}$ \\
\hline DMFT & $2.56 \pm 2.65$ & $2.34 \pm 2.40$ & $2.88 \pm 2.30$ & 0.55 \\
\hline $\mathrm{dmft}$ & $2.00 \pm 2.82$ & $2.56 \pm 2.25$ & $3.40 \pm 2.79$ & 0.50 \\
\hline
\end{tabular}

DMFT: Decayed missed filled teeth index for permanent dentition, $\mathrm{dmft}$ : Decayed missed filled teeth index for primary dentition, SD: Standard deviation

\section{Discussion}

It was stated that caries are associated with risk factors and sugar intake, while the mother's educational level and socioeconomic status are predictors $(9,10)$. Santos et al. (11) stated that there was a relationship between the lower socioeconomic status of mothers and the higher prevalence of caries in their children. Tinanoff and Reisine (12) stated that children from low socioeconomic status are likely to have more early childhood caries during the preschool age. Pinto et al. (13) also announced that higher socioeconomic status was a protective factor against the occurrence of dental caries. That study presented all mothers had a similar educational level and similar low socioeconomic status. Mothers with high socioeconomic status were not included in this study. For this reason, it is difficult to assign that there was a relationship between low socioeconomic status and lower education level among the mothers. It was found that there was a relationship between the DMFT scores of the children and their mothers' monthly income in the present study. The main finding of this study is that the mothers' socioeconomic status significantly affects their children's caries incidence. The caries incidence of those children whose mothers have high income was lower than those of children whose mothers have either moderate or low income.

The second finding of this study is that there was a relationship between the mothers' level of education

Table V. Association between caries of the children (DMFT, $\mathrm{dmft}$ ) and their mothers' education level

\begin{tabular}{|l|l|l|l|l|}
\hline \multicolumn{5}{|l|}{ Mother's education level } \\
\hline $\begin{array}{l}\text { Caries } \\
\text { value }\end{array}$ & $\begin{array}{l}\text { Primary- } \\
\text { secondary school }\end{array}$ & $\begin{array}{l}\text { High } \\
\text { school }\end{array}$ & University & p \\
\hline DMFT & $2.60 \pm 2.37$ & $2.77 \pm 2.42$ & $2.44 \pm 2.55$ & 0.93 \\
\hline dmft & $3.00 \pm 2.65$ & $2.20 \pm 1.92$ & - & 0.61 \\
\hline
\end{tabular}

DMFT: Decayed missed filled teeth index for permanent dentition, dmft: Decayed missed filled teeth index for primary dentition

Table VI. Association between frequency of consuming sweets of children and their mothers' education level

\begin{tabular}{|l|l|l|l|l|}
\hline & \multicolumn{3}{|l|}{ Mother's education level } & \\
\hline $\begin{array}{l}\text { Frequency of } \\
\text { consuming } \\
\text { sweets of } \\
\text { children }\end{array}$ & $\begin{array}{l}\text { Primary- } \\
\text { secondary } \\
\text { school }\end{array}$ & $\begin{array}{l}\text { High } \\
\text { school }\end{array}$ & University & p \\
\hline Once a day & $25 \%$ & $15.4 \%$ & $55.6 \%$ & 0.23 \\
\hline $2-3$ times a day & $69.2 \%$ & $76.9 \%$ & $33.3 \%$ & \\
\hline $\begin{array}{l}\text { 4 or more times } \\
\text { a day }\end{array}$ & $5.8 \%$ & $7.7 \%$ & $11.1 \%$ & \\
\hline
\end{tabular}


and their children's toothbrushing habit. Goldenfum et al. (14) also stated that when there was a higher mother's educational level, the frequency of children's toothbrushing increased to three times a day. It was stated in another study that the mothers' higher level of oral health knowledge was associated with their children's twice-daily toothbrushing (15). In this study, it was also found that there was a positive correlation between the mothers' education level and their children's toothbrushing frequency. As the mothers' level of education increased, the frequency of their children's toothbrushing increased.

The third finding of this study is that there was no relationship between the mothers' level education and their children's caries incidence. Folayan et al. (16) also stated that the mothers' and their children's knowledge of caries preventive measures were not predictors of the presence of caries.

The fourth finding of this study is that there was no relationship between the mothers' level of education and their children's frequency of consuming sweets. It was stated that there was a correlation between the high prevalence of caries and sugar consumption (17). Goldenfum et al. (14) also stated that the frequency of sugar intake could be considered as risk indicators for caries in the child population. Another study also showed that an increase of the caries index was associated with sugar consumption in children (18). It was also shown in this study that an increase of the caries indices in children was associated with their frequency of consuming sweets. However, no relationship between the frequency of consuming sweets of children and their mothers' level of education was found in this study.

The fifth finding of this study is that there was no relationship between the frequency of the mothers' toothbrushing and the number of caries of their children. However, as the frequency of toothbrushing of the mothers increased, the frequency of toothbrushing of their children increased. Shearer et al. (8) also stated that the mothers' oral hygiene and habits could have an impact on their children's oral health and could be a risk indicator for poor oral health among the offspring later in their adulthood. Rahbari et al. (19) study revealed that there was also a significant relationship between the frequencies of the mother's toothbrushing and the frequency of their children's toothbrushing.

\section{Study Limitations}

The sixth finding of this study is that there was a relationship between the ages of the mothers and the caries indices of their children. As the age of the mothers increased, the caries values of their children decreased with those mothers whose ages were between 31-45 years in this study. Similar results were not found in those mothers younger than 31 years or older than 45 years. There were no similar results or implications to compare the results of this current conclusion with.

\section{Conclusion}

It was observed that the age, education level, toothbrushing habit and socioeconomic status of mothers have a significant effect on the oral health of their children. A mother's oral hygiene and brushing habits could affect her child's oral health. However, in this study, it was observed that the children's caries incidence was not affected by their mothers' habits.

Ethics

Ethics Committee Approval: Ethical approval for this study was given by the Ethics Committee of the University and Ministry of Health Provincial Health Directorate Dental Hospital Chief Physician (approval number: 2019/02).

Informed Consent: Consent was obtained from her parents.

Peer-review: Externally peer-reviewed.

\section{Authorship Contributions}

Surgical and Medical Practices: B.K., I.U., Concept: B.K., I..U., Design: B.K., I.U., Data Collection: B.K., I.U., Analysis and Interpretation: B.K., I.U., Literature Search: B.K., I.U., Writing: B.K., I.U.

Conflict of Interest: No conflict of interest was declared by the authors.

Financial Disclosure: The authors declared that this study received no financial support.

\section{References}

1. Paglia L. Friuli S, Colombo S, Paglia M. The effect of added sugars on children's health outcomes:Obesity, Obstructive Sleep Apnea Syndrome (OSAS), Attention-Deficit/Hyperactivity Disorder (ADHD) and Chronic Diseases. European Journal of Paediatric Dentistry 2019; 20:127-32.

2. Paglia L. Oral prevention starts with the mother. European J of Paediatric Dent 2019; 20:173.

3. Alhabdan YA, Albeshr AG, Yenugadhati N, Jradi H. Prevalence of dental caries and associated factors among primary school children: a population-based cross-sectional study in Riyadh, Saudi Arabia. Environ Health Prev Med 2018; 23:60.

4. Silva JS, Silva FDSCM, Forte FDS, Sampaio FC. Caries prevalence and risk indicator among 2- to 6-year-old children at the clinic of preventive dentistry of the UFPB. Revista Odonto Ciência 2006; 21:17-21. 
5. Pieper $K$, Drerrler $S$, Heinzel-Gutenbrunner $M$, Neuhäuser $A$, Krecker $M$, Wunderlich $\mathrm{K}$, Jablonski-Momeni $A$. The influence of social status on pre-school children's eating habits, caries experience and caries prevention behaviour. Int I Public Health 2012; 57:207-15.

6. Peres MA de Oliveira Latorre Mdo R, Sheiham A, Peres KG, et al. Social and biological early life influences on severity of dental caries in children aged 6 years. Community Dent Oral Epidemiol 2005; 33:53-63.

7. Adeniyi OO, Ogunbodede EO, Jeboda SO, Folayan MO. Do maternal factors influence the dental health status of Nigerian preschool children. Int J Paediatr Dent 2009; 19:448-54.

8. Shearer DM, Thomson WM, Broadbent JM, Poulton R. Maternal oral health predicts their children's caries experience in adulthood. J Dent Res 2011; 90:672-7.

9. Corrêa-faria P, Paixão-gonçalves S, Paiva SM, Pordeus IA. Incidence of dental caries in primary dentition and risk factors: a longitudinal study. Braz Oral Res 2016; 30.

10. Lopes LM, Vazquez FL, Pereira AC, Romão DA. Indicators and risk factors of dental caries in children in Brazil - a literature review. RFO UPF 2014; 19.

11. Santos Junior V, Sousa RM, Oliveira MC, Caldas Junior AF, Rosenblatt A. Early childhood caries and its relationship with perinatal, socioeconomic and nutritional risks: a cross-sectional study. Oral Health 2014; 6:47.
12. Tinanoff, N, Reisine, S. Update on early childhood caries since the Surgeon General's Report. Acad Pediatr 2009; 9:396-403.

13. Pinto GDS, Azevedo MS, Goettems ML, Correa MB, Pinheiro RT, Demarco F. Are Maternal Factors Predictors for Early Childhood Caries? Results from a Cohort in Southern Brazil. Braz Dent I 2017; 28:391-7.

14. Goldenfum GM, Silva NC, Almeida LA, et al. Risk indicators of caries lesion activity in children. European Journal of Paediatric Dentistry 2019; 20:179-82.

15. Saied-Moallemi Z, Virtanen II, Chofranipour F, Murtomaa H Influence of mothers' oral health knowledge and attitudes on their children's. European Archives of Paediatric Dentistry 2008; 9:79-83.

16. Folayan MO, Kolawole KA, Oyedele T, et al. Association between knowledge of caries preventive practices, preventive oral health habits of parents and children and caries experience in children resident in sub-urban Nigeria. BMC Oral Health 2014; 14:156.

17. Valentak L), Najzar-Fleger D, Rajic Z. Effect of Diet and Dietary Habits on Caries. Acta Stomatol Croat 1995; 29:41-6.

18. Elidrissi SM, Naidoo ES. Prevalence of dental caries and toothbrushing habits among preschool children in Khartoum State, Sudan. International Dental Journal 2016; 66:215-20.

19. Rahbari M, Gold J. Knowledge and behaviours regarding early childhood caries among low-income women in Florida: a pilot study. I Dent Hyg 2015; 89:132-8. 